\title{
Efficacy of Proprioceptive Training with Prokin System in Balance Disorders from Multiple Sclerosis
}

Angelo Paolo Amico ${ }^{*}$ Mattia Nisi, llaria Covelli, Angela Maria Polito, Sabino Damiani, Giancarlo lanieri, Marisa Megna and Pietro Fiore

Policlinico of Bari, Bari, Italy

*Corresponding author: Angelo Paolo Amico MD, Medical Director, Policlinico of Bari, Spinal Unit, Piazza G. Cesare 81, Bari, Bari 70100, Italy, Tel: +393490576970;

E-mail: paolo-amico@alice.it

Received date: May 27, 2014, Accepted date: Jul 03, 2014, Published date: Jul 20, 2014

Copyright: @ 2014 Amico AP, et al. This is an open-access article distributed under the terms of the Creative Commons Attribution License, which permits unrestricted use, distribution, and reproduction in any medium, provided the original author and source are credited.

\section{Abstract}

Background: The multiple sclerosis is often associated with motor impairment and disorders of gait and balance, which are thought to be the main causes of the worsening of quality of life and functional autonomy. Many people with multiple sclerosis have a higher incidence of falls than healthy people, so that they risk more traumas; the lack of movement related to the motor impairment is therefore enhanced by the fear of falls.

Aims: To assess the efficacy of the "Prokin"system, composed of balance board and visual/acoustic feedback, associated with conventional proprioceptive training in increasing static and dynamic balance, proprioception, coordination and functional autonomy in patients with multiple sclerosis and to compare it with conventional physical therapy.

Methods: We enrolled 23 patients with defined SM (4 men, 19 women) divided into 2 groups (A and B).

Patients of group A (14) underwent 2 series of 10 sessions of 2-a-week proprioceptive training with Prokin system; patients of group B (5) underwent 2 series of 10 sessions of a 3-a-week conventional balance training. Each patient was assessed at t0 (before training), $\mathrm{t} 1$ (after 10 sessions) and $\mathrm{t} 2$ (after 20 sessions) with clinical scales for balance control (Tinetti, Berg) and autonomy (Barthel), and with instrumental tests (stabilometry, analyzing sway area, length of track and sway speed; and proprioceptive multiaxial assessment, exploring the Average Track Error).

Results: In group A we found statistically significant $(p<0,05)$ differences between the mean scores of all the clinical and instrumental assessments at $\mathrm{t} 0$ and at $\mathrm{t} 2$, in the sense of a better postural stability, cohordination and autonomy. No significant differences were found from to to $\mathrm{t} 2$ in group B. Conclusions: Our study showed that this new kind of proprioceptive training (Prokin) is more able to ameliorate balance, motor performance and global autonomy in patients with multiple sclerosis than conventional therapy. This allows the patients to move themselves and walk with more safety, preventing falls and traumatic events.

Keywords Multiple sclerosis; Balance disorders; Proprioception; Rehabilitation

\section{Introduction}

Multiple sclerosis (MS) is a chronic progressive disorder of the central nervous system which affects a large number of neurologic functions (cognitive function, visual function, muscular strength and tone, sensitivity and coohordination) [1]. The motor symptoms of MS like fine alterations of the balance and of the gait [2] are considered the main responsibles for the worsening of the quality of life and of independence, overall in patients with recent diagnosis, who are still free from clinical disability $[3,4]$. Disorders of balance and underlying functions are common in persons with MS [5-10]. A recent review about the postural control in MS showed the presence of a balance impairment characterized from wider sways in standing position, a delay in the reactions of re-balancing, and a reduced ability to move over the limits of stability [11]. Many people with MS have frequent falls $[12,13]$, fear to fall [14], and increased risk of injuries after falls $[15,16]$.
According to the World Health Organization (WHO) and the International Classification of Functioning, Disability and Health (ICF), the balance is defined as "modifications and maintaining the position of the body" [2]. The maintainance of the standing position and the balance require the integration of different sensitive and motor inputs (visual, vestibular, proprioceptive) in order to generate cohordinated movements which hold the centre of pressure within the limits of stability $[17,18]$. The balance is a complex function which depends upon peripheral esteroceptive and proprioceptive inputs, integration and processing of these at a central level (brain and cerebellum) and a correct motor output, which also comes from mechanisms of feedback, mainly for static balance, and feedforward, mainly for dynamic balance.

In the last years many different therapeutic approaches were proposed for balance training $[18,19]$, including a strategy of motor and multisensorial training, endurance training, aerobic exercise, but only in a few cases the training is based on giving inputs to both visual and somato-sensitive and vestibular systems, which are often altered in persons with multiple sclerosis. 
Classically patients with MS were suggested to limit their levels of physical activity, in order to prevent the phenomenon of the central fatigue, but recent studies evidenced the benefits of exercise [20-24] without any described adverse reactions [20,25-28]. The controlled physical activity was shown to be related to better mobility, gait, muscular strength and fitness [1,9-29]. In a review, regular therapeutic exercise was associated with a little better quality of life in people with MS [30]. Other benefits may include less faticability, reduced depression and anxiety [29,31]; besides an early treatment can contribute to slow or prevent the worsening of the physical disability [32-34]. However people with multiple sclerosis typically do less physical activity compared to general population $[21,23,35]$, and this can lead to deconditioning, sickness, reduced self-esteem, increase of the levels of disability [23], such as risk factors like cardiovascular diseases, obesity, diabetes and limitation of participation to common activities and interactions with other people, fundamental for the psychologic wellness.

A pilot study suggests that the domestic use of Nintendo Wii in patients with MS can give advantages for the balance, through exercises created by a commercial software, aimed to the stimulation of proprioception [36,37].

The evidence-based techniques of rehabilitation are of great interest for the treatment of patients affected from MS, yet nowadays we need more information about the relationship between physical therapy and balance disorders.

In consideration of these issues and of the fact that, in other neurologic diseases with balance disorder like Parkinson's disease [38], proprioceptive training was efficient in increasing the postural stability, we proposed a particular kind of proprioceptive training in patients with multiple sclerosis, using the Prokin system.

\section{Aims}

Our aims were to assess the efficacy of the "Prokin" system, composed of balance board and visual/acoustic feedback, associated with conventional proprioceptive training (PNF, Proprioceptive Neuromuscolar Facilitation according to Kabat) in increasing static and dynamic balance, proprioception, coordination and functional autonomy in patients with multiple sclerosis and to compare it with conventional physical therapy.

\section{Materials and Methods}

In the period from january 2012 till april 2014 in our ambulance of Complex Unit of Physical Medicine and Rehabilitation at the Policlinico of Bari the we visited 50 patients with MS from which we excluded:

- Not defined MS diagnosis

- Patients aged $>60$ or $<18$

- EDSS $>6$ or $<3$

- MS with a progressive clinical course

- Patients with poussées

- Therapy with immunosuppressors or interpheron

So from these patients we enrolled 23 patients, from which we randomized 14 patients for group A and 5 patients for group B.

\begin{tabular}{|l|l|l|l|l|l|l|l|l|l|l|l|}
\hline & Population & Mean age & $\begin{array}{l}\text { Median } \\
\text { Age }\end{array}$ & $\begin{array}{l}\text { Age Dev. } \\
\text { Std. }\end{array}$ & $\begin{array}{l}\text { Lowest } \\
\text { Age }\end{array}$ & $\begin{array}{l}\text { Highest } \\
\text { Age }\end{array}$ & $\begin{array}{l}\text { Median } \\
\text { media }\end{array}$ & $\begin{array}{l}\text { Mean } \\
\text { EDSS }\end{array}$ & $\begin{array}{l}\text { EDSS Dev. } \\
\text { Std }\end{array}$ & $\begin{array}{l}\text { Lowest } \\
\text { EDSS }\end{array}$ & $\begin{array}{l}\text { Highest } \\
\text { EDSS }\end{array}$ \\
\hline & 23 & 39,69 & 39 & 10 & 26 & 58 & 4,80 & 4,5 & 1,05 & 3 \\
\hline Sex & Population & Mean age & $\begin{array}{l}\text { Median } \\
\text { Age }\end{array}$ & $\begin{array}{l}\text { Age Dev. } \\
\text { Std. }\end{array}$ & Lowest Age & $\begin{array}{l}\text { Highest } \\
\text { Age }\end{array}$ & & & & \\
\hline Male & 4 & 39,5 & 40,5 & 8,34 & 29 & 48 & 4,75 & 5 & 1,32 & 3 \\
\hline Female & 19 & 39,73 & 39 & 10,51 & 26 & 58 & 4,81 & 4,5 & 1,03 & 3 \\
\hline
\end{tabular}

Table 1: Statistical data and sampling of our patients.

Nineteen female patients, four males. The age range was 26-58 years, with a mean age of 39.69 years.

We recorded 4 drop-outs: one patient was excluded due to an exacerbation of the disease during treatment, three others gave up the study for personal problems.

\section{PROKIN $^{\circledR}$ system}

Prokin is an advanced technology that combines classic tilting platform connected to a monitor and speaker to create a visual and audio feedback in response to minimal movements of the platform on all plans; analysis and integration of on-screen tracks described by the patient (with the movements that focus on the ankle articulation) is realized by special software in order to generate targeted rehabilitation paths for the areas where the proprioceptive impairment is clearer.

The same system also includes the possibility to perform a proprioceptive multiaxial assessment.
When patient is on the tilting platform, he has to direct his concentration on the monitor on which the tracks that are his target should display: the patient will draw lines on the screen moving his foots and his motor task will be to try to keep the lines drawn by the movements of his foot as much as possible superimposed on those already drawn by the system.

The movement of the platform is faithfully reproduced on the screen so that the patient can see it and correct it.

The system also beeps with intensity and tone proportional to the deviation of the track drawn by the patient from the reference path.

The control system of the balance board, consisting essentially of a data acquiring board able to electronically translate all the minimum angular displacements made by the board, converts each movement into electrical signals which are then processed by a personal computer and displayed on screen. 
The result is very useful for both the patient and the operator: the patient may have a continuous visual feedback that allows him to establish a comparison between what "feels" (kinesthetic level) and what really produces.

The objective evaluation allows the rehabilitator to understand if the patient gradually recovers the kinetic energy of motion perception.

The system is also able to store the traces obtained from the patient and can automatically store in a personal folder, allowing, in this way, a subsequent comparison between the paths themselves.

All patients were subjected to the time $\mathrm{t} 0$ to:

- Careful history and Physiatric examination

\section{- Rating scales:}

Barthel scales (n. 10 items with a maximum score 100, investigates the functional autonomy

Tinetti balance scale (no. 25 items, divided into two parts with maximum score 32, explores the balance and gait)

Berg balance scale (no. 14 items with a maximum score 56, investigates the static and dynamic balance)

- Stabilometry concerned with BPE, in particular, the registration of: length of the ball $(\mathrm{OA}+\mathrm{OC})$ in $\mathrm{mm}$

dell'elissi Area $(\mathrm{OA}+\mathrm{OC})$ in $\mathrm{mm}^{2}$

average speed of the oscillations $(\mathrm{OA}+\mathrm{OC}) \mathrm{mm} / \mathrm{s}$

The stabilometric examination is an integral part of Milletrix software dedicated to baropodometry.

- Functional multiaxial proprioceptive examination by implemented software in the Prokin

To all patients has been proposed a proprioceptive training (to perform through the Prokin system) consisting of two series from 10 sessions each of proprioceptive training that included 2 sessions/ week, for a total of 10 weeks. 17 of the 23 patients have accepted our proposal became part of the experimental group (group A) and 6 refused for logistical problems or other becoming a control group (group B).

The patients belonging to group B (now 5 because of a drop-outs) were initiated in the normal seriess of conventional proprioceptive training (PNF, Proprioceptive Neuromuscolar Facilitation according to Kabat) and were tested at time t1 (after ten sessions of FKT) and at time 2 (end of series of FKT) with:

- Rating scales: Barthel, Tinetti, Berg

- Stabilometry concerned with BPE, in particular, the registration of: length of the track $(\mathrm{OE}+\mathrm{CE})$ area of the ellipse $(\mathrm{OE}+\mathrm{CE})$ average speed $(\mathrm{OE}+\mathrm{CE})$

- Evaluation by proprioceptive multiaxial system that can detect Prokin that show:

Average \% of "errors" in the path of the proposed assessment: ATE index (Average Track Error)

The patients belonging to group A (now 14 due to 3 drop-outs) were initiated in conventional proprioceptive training (PNF, Proprioceptive Neuromuscolar Facilitation according to Kabat) and two seriess of ten sessions each of proprioceptive training system administered by Prokin twice a week and have been tested at time t1 (after the first series) and at time $\mathrm{t} 2$ (at the end of the second series) with:

- Rating scales: Barthel, Tinetti, Berg

- Stabilometry concerned with BPE, in particular, the registration of: length of the track $(\mathrm{OE}+\mathrm{CE})$

area of the ellipse $(\mathrm{OE}+\mathrm{CE})$ average speed $(\mathrm{OE}+\mathrm{CE})$

- Evaluation by proprioceptive multiaxial system that can detect Prokin that show:

Average \% of "errors" in the path of the proposed assessment: ATE index (Average Track Error)

In each session of proprioceptive training each patient was subjected to functional evaluation proprioceptive that has revealed:

Average \% of "errors" in the path of the proposed assessment: ATE index (Average Track Error)

The system specifies the distribution in areas where they split the imaginary circle that represents the full ROM of the joint TT (8 sectors, each extended to 45 degrees).

On the basis of the functional profile emerged in each session of proprioceptive training are offered to the patient:

- - 9 tracks rehabilitative distributed in 3 areas proved more deficient (considering the most deficient in those areas that, on average, showed the greatest number of errors ATE and the greater variance of the force)

- - 4 tracks on circuits rehabilitation aimed at improving dexterity and disequilibrium (proposed by the software Prokin)

The first series included the use of the limb resulted more deficient both at the clinical evaluation (more spastic according to the Ashworth scale modified and / or with less muscle strength according to the MRC scale) and with the instrumental by multiaxial proprioceptive evaluation, the second series included the other limb.

The physical therapist who performed the conventional therapy was the same for both groups and was blinded about the use of prokin or not. Treatment with Prokin was performed by another therapist always the same.

All tretaments were administered in antemeridian hours (9:00-12:00).

\section{Results}

\section{Functional assessment by Berg, Tinetti and Barthel scale}

Group A: The data obtained at time $\mathrm{t} 0$ and at time $\mathrm{t} 2$ were analyzed using the Student t-test for paired samples and Wilcoxon test and processed through the software of statistical StatPlus: mac 5.8.2.0 (AnalystSoft Inc.).

These comparisons showed that the differences between the averages of evaluations at time $\mathrm{t} 2$ and at time to of the items of the Tinetti (Chart 1), Berg (Chart 2) and Barthel scales (Chart 3) are different in a statistically significant ( $p$ value $<0.05$ ). In particular, are higher at time $\mathrm{t} 2$ (one-tailed $\mathrm{p}$ value $<0.05$ ). 


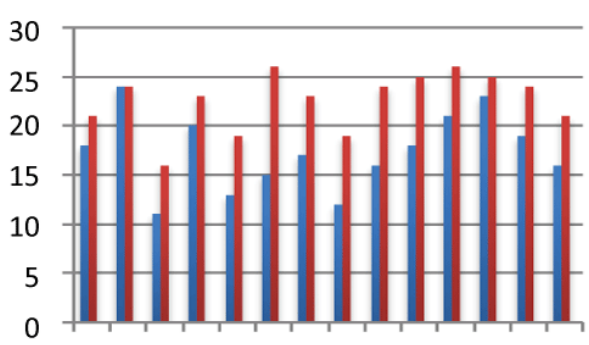

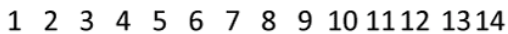

Chart 1: Tinetti scale score, comparison before $(\mathrm{t} 0)$ and after treatment ( $\mathrm{t} 2)$ in experimental group.

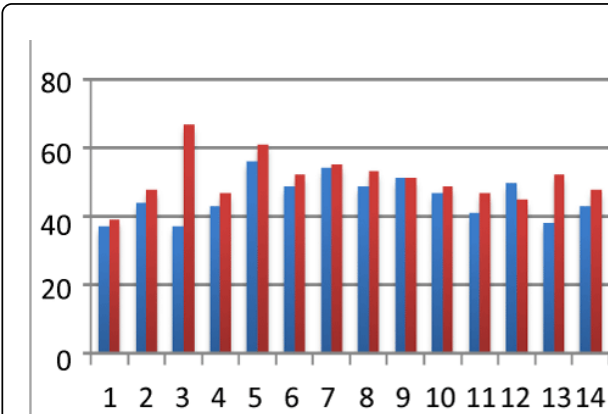

Chart 2: Berg scale score, comparison before (t0) and after treatment $(\mathrm{t} 2)$ in experimental group.

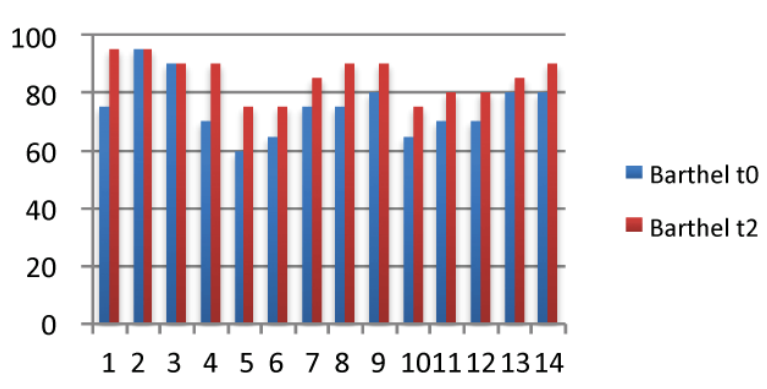

Chart 3: Barthel scale score, comparison before (t0) and after treatment $(\mathrm{t} 2)$ in experimental group.

Group B: Even in this case, the data obtained at time t0 and at time t2 were analyzed using the Student t-test for paired samples and Wilcoxon test and processed through the software of statistical processing StatPlus: mac 5.8.2.0 (AnalystSoft Inc.).

These comparisons showed that the differences between the averages of evaluations at time $\mathrm{t} 2$ and at time t 0 of the items of the Tinetti (Chart 4), Berg (Chart 5) and Barthel (Chart 6) scales are not different in a statistically significant ( $p$ value $\geq 0.05$ ).

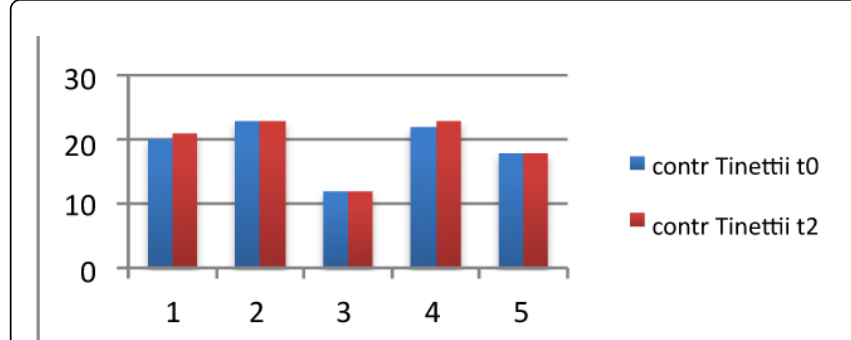

Chart 4: Tinetti scale score, comparison before (t0) and after treatment ( $\mathrm{t} 2$ ) in control group.

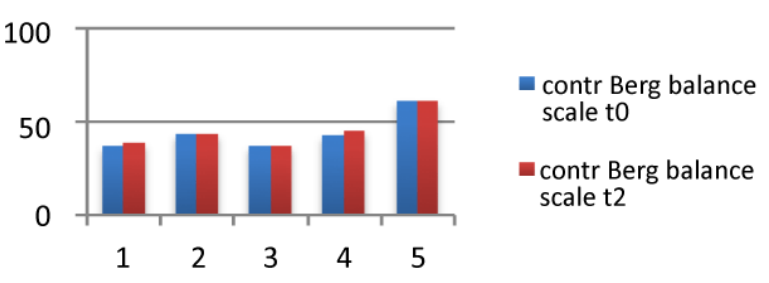

Chart 5: Berg scale score, comparison before (t0) and after treatment $(\mathrm{t} 2)$ in control group.

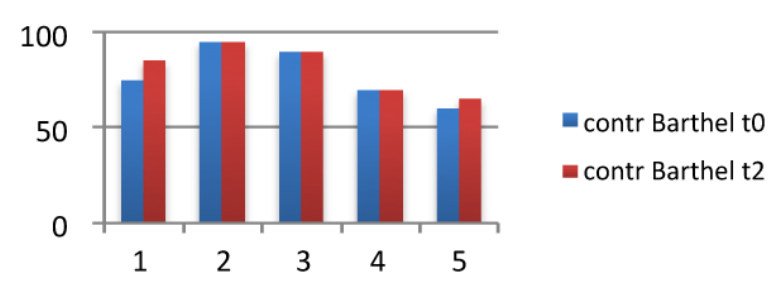

Chart 6: Barthel scale score, comparison before (t0) and after treatment $(\mathrm{t} 2)$ in control group.

\section{Stabilometric evaluation by BPE}

Group A: The data obtained at time t0 and at time $\mathrm{t} 2$ were analyzed using the Student $\mathrm{t}$-test for paired samples and processed through the software of statistical StatPlus: mac 5.8.2.0 (AnalystSoft Inc.).

These comparisons showed that the differences between the averages of evaluations at time $\mathrm{t} 2$ and at time $\mathrm{t} 0$ of the parameters obtained in BPE are different in a statistically significant ( $\mathrm{p}$ value $<0.05$ ) in both the sensitization test with open eyes and in the closed eyes and in particular are reduced (one-tailed $\mathrm{p}$ value $<0.05$ ).

- Area of the ellipse (Chart 7 and 8)

- Length of the track (Chart 9 and 10)

- Average Speed (Chart 11and 12) 
Citation: Amico AP, Nisi M, Covelli I, Polito AM, Damiani S, et al. (2014) Efficacy of Proprioceptive Training with Prokin System in Balance Disorders from Multiple Sclerosis. J Mult Scler 1: 110. doi:10.4172/jmso.1000110

Page 5 of 8

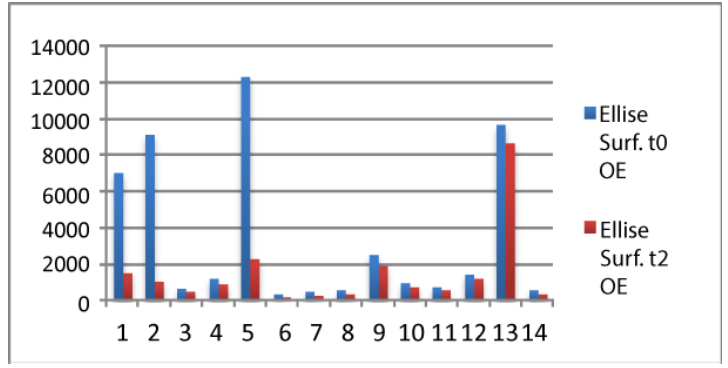

Chart 7: Sway area in opened eyes mode, comparison before (t0) and after treatment $(\mathrm{t} 2)$ in experimental group.

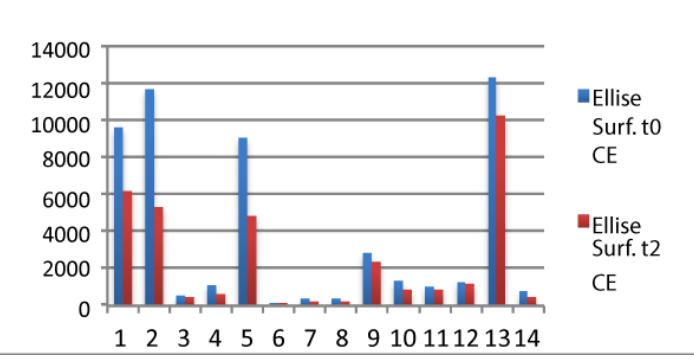

Chart 8: Sway area in closed eyes mode, comparison before (t0) and after treatment $(\mathrm{t} 2)$ in experimental group.

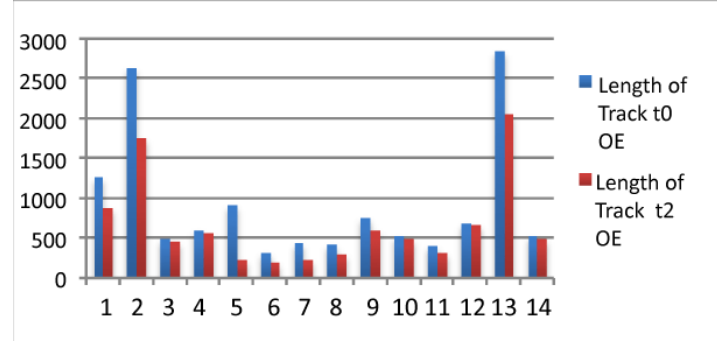

Chart 9: Length of track in opened eyes mode, comparison before $(\mathrm{t} 0)$ and after treatment $(\mathrm{t} 2)$ in experimental group.

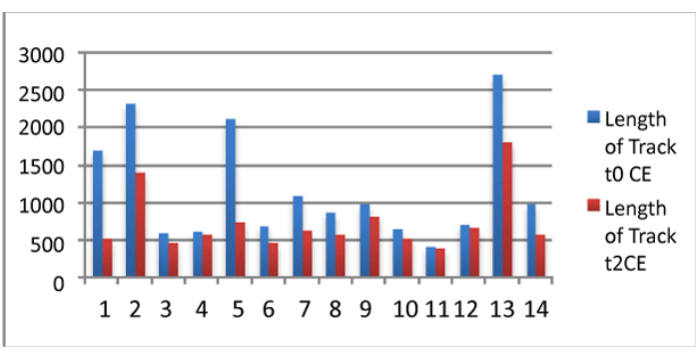

Chart 10: Length of track in closed eyes mode, comparison before (t0) and after treatment ( $\mathrm{t} 2$ ) in experimental group.

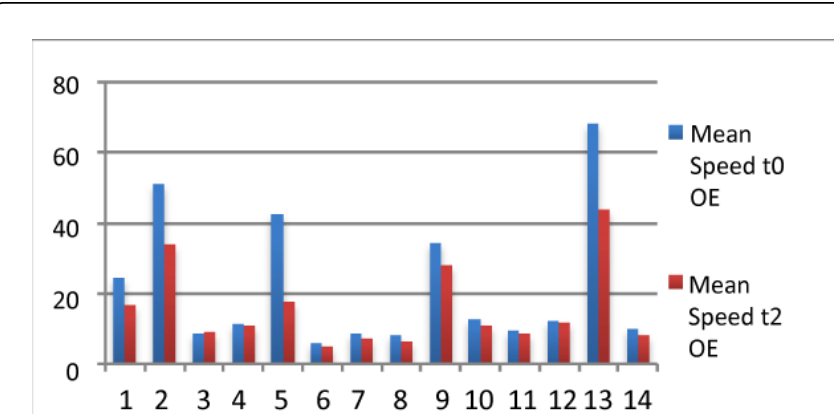

Chart 11: Mean Speed in opened eyes mode, comparison before (t0) and after treatment ( $\mathrm{t} 2$ ) in experimental group.

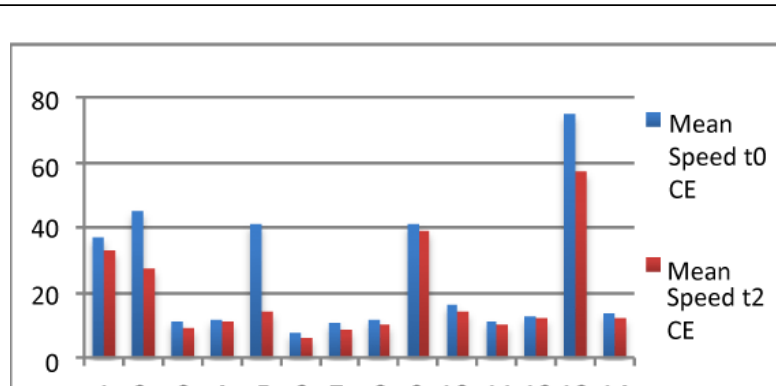

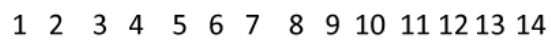

Chart 12: Mean Speed in closed eyes mode, comparison before ( $\mathrm{t} 0$ ) and after treatment $(\mathrm{t} 2)$ in experimental group.

Group B: The data obtained at time $\mathrm{t} 0$ and at time $\mathrm{t} 2$ were analyzed using the Student t-test for paired samples and processed through the software of statistical StatPlus: mac 5.8.2.0 (AnalystSoft Inc.).

These comparisons showed that the differences between the averages of evaluations at time $\mathrm{t} 2$ and at time $\mathrm{t} 0$ of the parameters obtained in BPE ellipse area (Chart 13 and 14), length ball (Chart 15 and 16), Average Speed (Chart 17and18) are not different in a statistically significant ( $p$ value $\geq 0.05$ ) in both the sensitization test with open eyes and in the eyes closed.

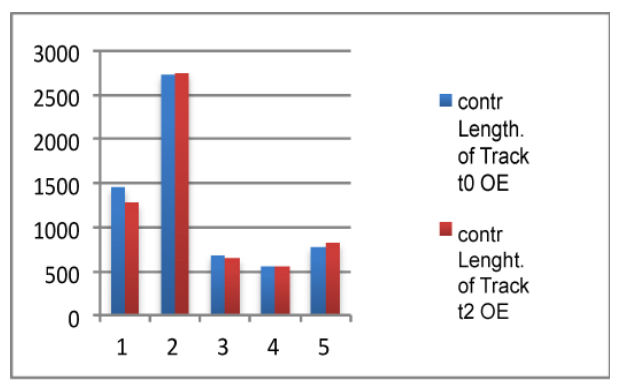

Chart 13: Length of track in opened eyes mode, comparison before (t0) and after treatment ( $\mathrm{t} 2$ ) in control group. 
Citation: Amico AP, Nisi M, Covelli I, Polito AM, Damiani S, et al. (2014) Efficacy of Proprioceptive Training with Prokin System in Balance Disorders from Multiple Sclerosis. J Mult Scler 1: 110. doi:10.4172/jmso. 1000110

Page 6 of 8

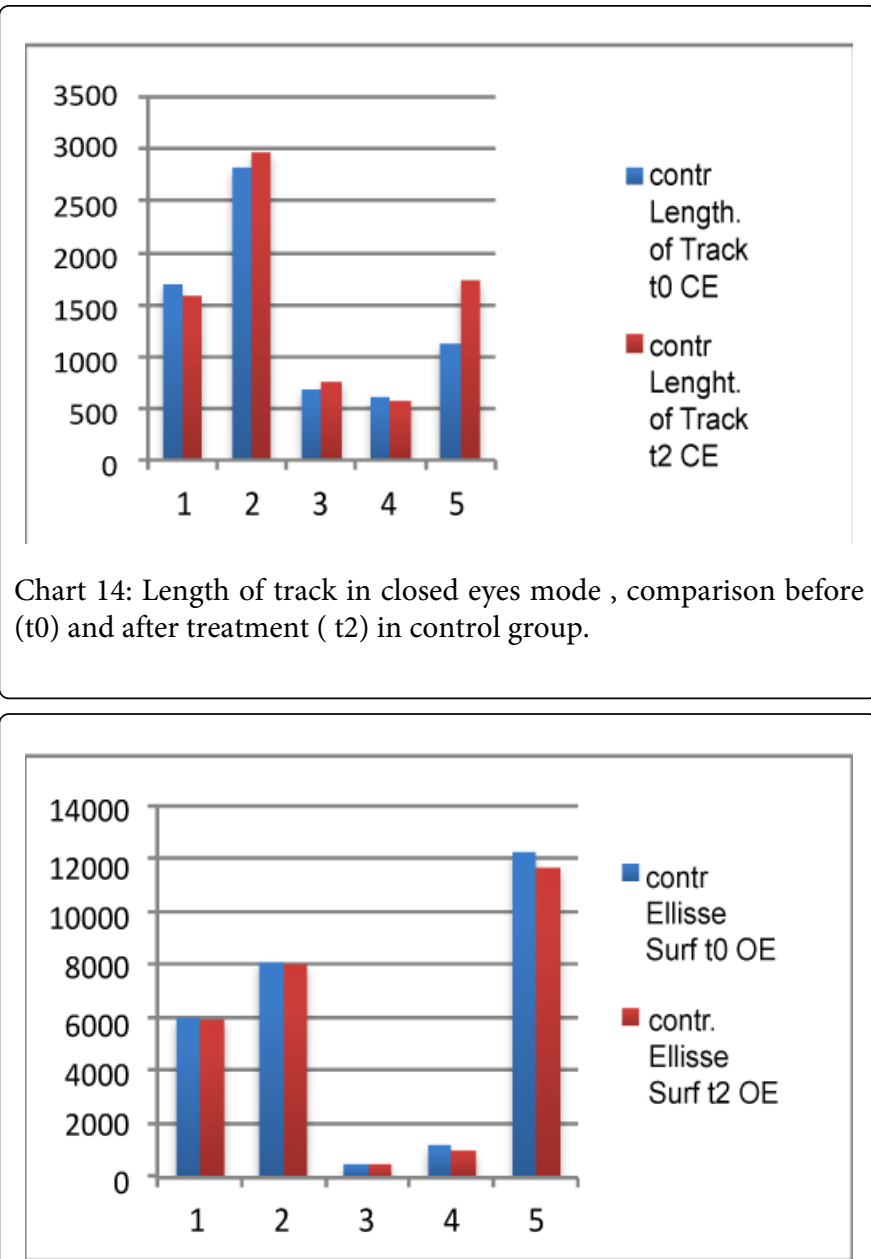

Chart 15: Sway area in opened eyes mode, comparison before (t0) and after treatment ( $\mathrm{t} 2$ ) in control group.

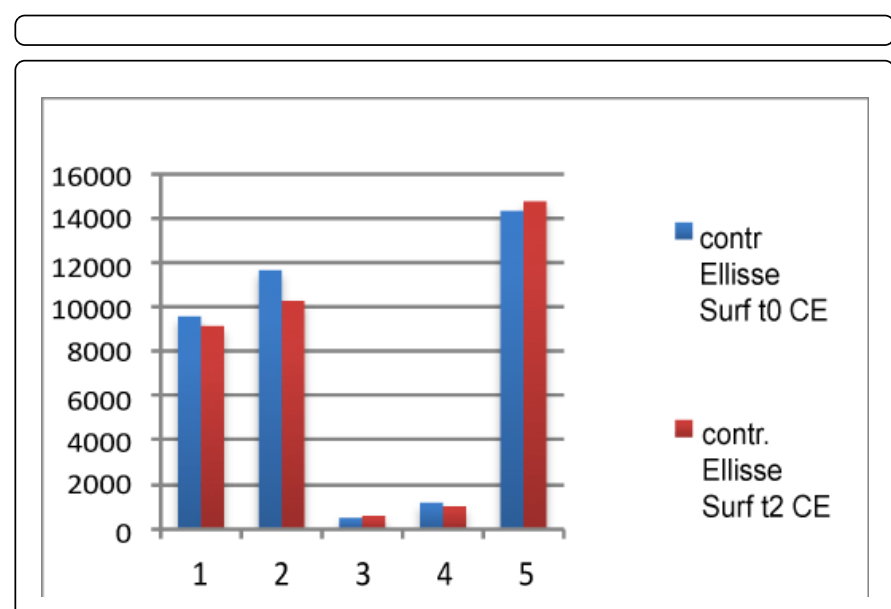

Chart 16: Sway area in closed eyes mode, comparison before (t0) and after treatment ( $\mathrm{t} 2$ ) in control group.

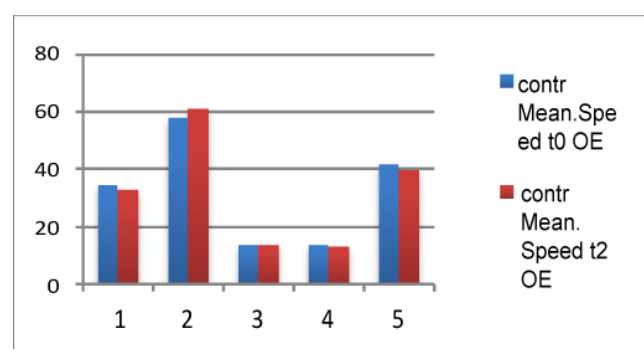

Chart 17: Mean speed in opened eyes mode, comparison before $(\mathrm{t} 0)$ and after treatment $(\mathrm{t} 2)$ in control group.

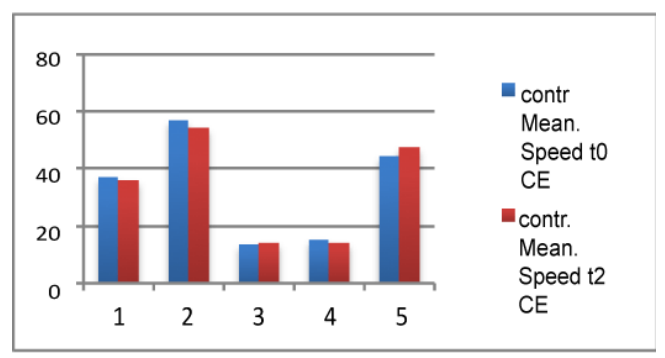

Chart 18: Mean speed in closed eyes mode, comparison before (t0) and after treatment ( $\mathrm{t} 2)$ in control group.

\section{Proprioceptive multiaxial assessment by the software implemented in Prokin}

The data obtained at time $\mathrm{t} 0$ and at time $\mathrm{t} 2$ were analyzed using the Student t-test for paired samples and processed through the software of statistical StatPlus: mac 5.8.2.0 (AnalystSoft Inc.).

These comparisons showed that the differences between the averages of evaluations at time $\mathrm{t} 2$ and at time $\mathrm{t} 0$ of the parameter ATE (average number of mistakes made in the layout of functional assessment proprioceptive multiaxial) differ in a statistically significant ( $\mathrm{p}$ value $<0.05$ ) and in particular are reduced (one-tailed $\mathrm{p}$ value $<0.05$ ) (Chart 19).

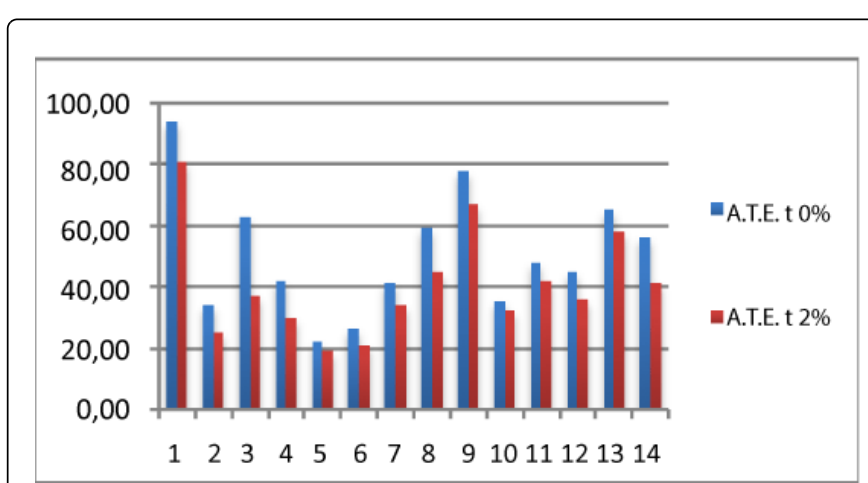

Chart 19: Average number of track errors (A.T.E.) comparison before $(\mathrm{t} 0)$ and after treatment $(\mathrm{t} 2)$ in experimental group. 
The data obtained at time $\mathrm{t} 0$ and at time $\mathrm{t} 2$ were analyzed using the Student t-test for paired samples and processed through the software of statistical StatPlus: mac 5.8.2.0 (AnalystSoft Inc.).

These comparisons showed that the differences between the averages of evaluations at time $\mathrm{t} 2$ and at time to of the parameter ATE are not different in a statistically significant ( $\mathrm{p}$ value $\geq 0.05$ ) (Chart 20).

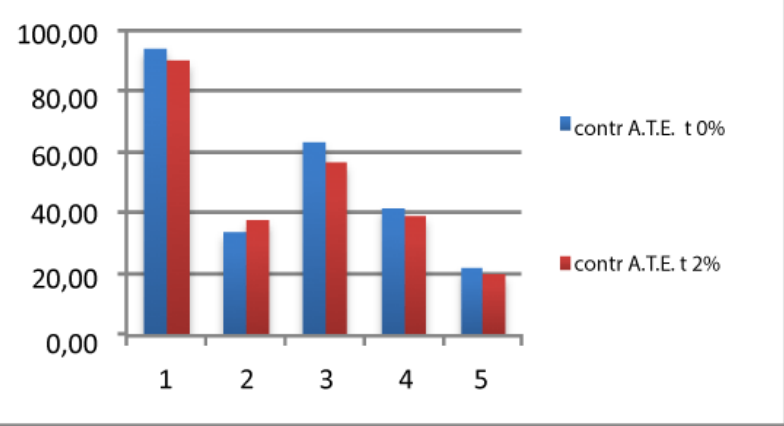

Chart 20: Average number of track errors (A.T.E.) comparison before $(\mathrm{t} 0)$ and after treatment $(\mathrm{t} 2)$ in control group.

The analysis of the outcome of the clinical rating scales showed a statistically significant improvement in static and dynamic postural stability in group A from to to $\mathrm{t} 2$ (for example: increase in the mean score of Tinetti scale from 17.35 to 22.77 and Berg balance scale from 45.64 to 51) and in functional autonomy, gait and postural transfers (increase in the average score of the Barthel from 75 to 85.66). The same analysis in group B did not show significant differences from t0 to t2.

The results of stabilometry confirm a statistically significant improvement of static balance in group A and in group B from t0 to t2, by reducing the length of the track , and the mean speed of sway (expression of energy expenditure required to maintain the body center of gravity within the polygon of support) and the area of the ellipse (an expression of the degree of instability). It should be noted that these values underwent proportional modifications in both the sensitization tests, with open eyes and with closed eyes.

The percentage of the average track error (ATE) showed a statistically significant reduction in group A from to to 2 , contrary to what happened in the group B; this represents an improvement in proprioception and motor coordination.

\section{Conclusions}

Multiple sclerosis often causes motor impairment, alteration of the gait quality and quantity, and alteration of the balance, which are considered the main causes of a worse quality of life and functional autonomy.

Many people with multiple sclerosis have a higher incidence of falls than healthy people, so that they risk more traumas; the lack of movement related to the motor impairment is therefore enhanced by the fear of falls.

Our study showed that if in the rehabilitative project of a patient with balance disorder from MS we include an adequate proprioceptive software-assisted training, he can gain better stability and less energy expenditure needed to maintain it. It is likely that a better stability also allows a better gait pattern and increased safety, with subsequent more autonomy in postural changes and in transfers.

Furthermore, this experiment, yet limited as to the number of treated patients, shows how the conventional physical therapy, isolated, does not determine significant modification of the analyzed parameters.

Another point is: since our stabilometric values are proportionally better (reduced) both with open eyes and with closed eyes, it is possible to suppose that the balance disorder of our patients was mainly related to an impairment of the cerebellar integration of inputs and that the proprioceptive stimulation, which acts through the somato-sensitive channel, associated with a visual cueing, may have generated a compensation strategy for the recovery of postural equilibrium.

For the next future it would be desireable to increase the number of studied subjects, to divide them as to specific anatomic sites of demyelinizing lesions and to analize the subscores of the assessment scales in order to compare the significance of the variations of the static balance with the one of the dynamic balance. The conventional physical therapy can take an important role in completing this kind of treatment, especially for altered functions, other than balance, in multiple sclerosis, such as muscular strength and tone.

\section{References}

1. Compston A, Coles A (2002) Multiple sclerosis. Lancet 359: 1221-1231.

2. World Health Organization (2001) International Classification of Functioning, Disability and Health (ICF).

3. Martin CL, Phillips BA, Kilpatrick TJ, Butzkueven H, Tubridy N, et al. (2006) Gait and balance impairment in early multiple sclerosis in the absence of clinical disability. Mult Scler 12: 620-628.

4. Casadio M, Sanguineti V, Morasso P, Solario C (2008) Abnormal sensorimotor control, but intact force field adaptation, in multiple sclerosis subjects with no clinical disability. Mult Scler 14: 330-342.

5. Jackson RT, Epstein CM, De l'Aune WR (1995) Abnormalities in posturography and estimations of visual vertical and horizontal in multiple sclerosis. Am J Otol 16: 88-93.

6. Corradini ML, Fioretti S, Leo T, Piperno R (1997) Early recognition of postural disorders in multiple sclerosis through movement analysis: a modeling study. IEEE Trans Biomed Eng 44: 1029-1038.

7. Karst GM, Venema DM, Roehrs TG, Tyler AE (2005) Center of pressure measures during standing tasks in minimally impaired persons with multiple sclerosis. J Neurol Phys Ther 29: 170-180.

8. Sosnoff JJ, Shin S, Motl RW (2010) Multiple sclerosis and postural control: the role of spasticity. Arch Phys Med Rehabil 91: 93-99.

9. Soyuer F, Mirza M, Erkorkmaz U (2006) Balance performance in three forms of multiple sclerosis. Neurol Res 28: 555-562.

10. Frzovic D, Morris ME, Vowels L (2000) Clinical tests of standing balance: performance of persons with multiple sclerosis. Arch Phys Med Rehabil 81:215-221.

11. Mills RJ, Yap L, Young CA (2007) Treatment for ataxia in multiple sclerosis. Cochrane Database Syst Rev : CD005029.

12. Cameron $\mathrm{MH}$, Lord S (2010) Postural control in multiple sclerosis: implications for fall prevention. Curr Neurol Neurosci Rep 10: 407-412.

13. Finlayson ML, Peterson EW, Cho CC (2006) Risk factors for falling among people aged 45 to 90 years with multiple sclerosis. Arch Phys Med Rehabil 87: 1274-1279. 
Citation: Amico AP, Nisi M, Covelli I, Polito AM, Damiani S, et al. (2014) Efficacy of Proprioceptive Training with Prokin System in Balance Disorders from Multiple Sclerosis. J Mult Scler 1: 110. doi:10.4172/jmso.1000110

Page 8 of 8

14. Peterson EW, Cho CC, Finlayson ML (2008) Fear of falling and associated activity curtailment among middle aged and older adults with multiple sclerosis. Arch Phys Med Rehabil 89: 1031-1037.

15. Peterson EW, Cho CC, von Koch L, Finlayson ML (2008) Injurious falls among middle aged and older adults with multiple sclerosis. Arch Phys Med Rehabil 89: 1031-1037.

16. Cameron MH, Poel AJ, Haselkorn JK, Linke A, Bourdette D (2011) Falls requiring medical attention among veterans with multiple sclerosis: a cohort study. J Rehabil Res Dev 48: 13-20.

17. Shumway-Cook A, Woollacott MH (2001) Normal postural control. In: Shumway-Cook A, Woollacott MH, editors. Motor control: theory and practical applications. Lippincott Williams \& Wilkins, Baltimore, pp. 163-191.

18. Rose DJ (2010) FallProof: a comprehensive balance and mobility training program (2nd edn) Human Kinetics, Champaign IL, pp. 3-10.

19. Huxham FE, Goldie PA, Patla AE (2001) Theoretical considerations in balance assessment. Aust J Physiother 47: 89-100.

20. Rietberg MB, Brooks D, Uitdehaag BM, Kwakkel G (2005) Exercise therapy for multiple sclerosis. Cochrane Database Syst Rev : CD003980.

21. Motl RW, McAuley E, Snook EM (2005) Physical activity and multiple sclerosis: a meta-analysis. Mult Scler 11: 459-463.

22. Dalgas U, Stenager E, Ingemann-Hansen T (2008) Multiple sclerosis and physical exercise: recommendations for the application of resistance-, endurance- and combined training. Mult Scler 14: 35-53.

23. McConnell A (2008) Can physical activity bring benefit to people with MS? Sport Exerc Scientist 12: 12-13.

24. Motl RW, Pilutti LA (2012) The benefits of exercise training in multiple sclerosis. Nat Rev Neurol 8: 487-497.

25. Ponichtera-Mulcare JA (1993) Exercise and multiple sclerosis. Med Sci Sports Exerc 25: 451-465.

26. Smith RM, Adeney-Steel M, Fulcher G, Longley WA (2006) Symptom change with exercise is a temporary phenomenon for people with multiple sclerosis. Arch Phys Med Rehabil 87: 723-727.

27. Tallner A, Waschbisch A, Wenny I, Schwab S, Hentschke C, et al. (2012) Multiple sclerosis relapses are not associated with exercise. Mult Scler 18 232-235.
28. Tarakci E, Yeldan I, Huseyinsinoglu BE, Zenginler Y, Eraksoy M (2013) Group exercise training for balance, functional status, spasticity, fatigue and quality of life in multiple sclerosis: a randomized controlled trial. Clin Rehabil 27: 813-822.

29. Latimer-Cheung A, Pilutti LA, Hicks AL Martin Ginis KA, Fenuta AM, et al. (2013) Effects of exercise training on fitness, mobility, fatigue, and health-related quality of life among adults with multiple sclerosis: a systematic review to inform guideline development. Arch Phys Med Rehabil 94: 1800-1828.

30. Motl RW, Gosney JL (2008) Effect of exercise training on quality of life in multiple sclerosis: a meta-analysis. Mult Scler 14: 129-135.

31. Feinstein A, Rector N, Motl R (2013) Exercising away the blues: can it help multiple sclerosis-related depression? Mult Scler 14: 1815-1819.

32. Solari A, Filippini G, Gasco P, Colla L, Salmaggi A, et al. (1999) Physical rehabilitation has a positive effect on disability in multiple sclerosis patients. Neurology 52: 57-62.

33. Heesen C, Romberg A, Gold S, Schulz KH (2006) Physical exercise in multiple sclerosis: supportive care or a putative disease-modifying treatment. Expert Rev Neurother 6: 347-355.

34. Dalgas U, Stenager E (2012) Exercise and disease progression in multiple sclerosis: can exercise slow down the progression of multiple sclerosis? Ther Adv Neurol Disord 5: 81-95.

35. Marrie R, Horwitz R, Cutter G, Tyry T, Campagnolo D, et al. (2009) High frequency of adverse health behaviors in multiple sclerosis. Mult Scler 15: 105-113.

36. Thomas S, Fazakarley L, Thomas PW, Brenton S, Collyer S, et al. (2014) Testing the feasibility and acceptability of using the Nintendo Wii in the home to increase activity levels, vitality and well-being in people with multiple sclerosis (Mii-vitaliSe): protocol for a pilot randomised controlled study. BMJ Open.4: e005172.

37. Brichetto G, Spallarossa P, de Carvalho ML, Battaglia MA (2013) The effect of Nintendo ${ }^{\oplus}$ Wii $^{\oplus}$ on balance in people with multiple sclerosis: a pilot randomized control study. Mult Scler 19: 1219-1221.

38. Azarpaikan A, Torbati HT, Sohrabi M (2014) Neurofeedback and physical balance in Parkinson's patients. Gait Posture 40: 177-181. 